\title{
Short- and long-term reliability of adult recall of vegetarian dietary patterns in the Adventist Health Study-2 (AHS-2)
}

\author{
Marcia C. Teixeira Martins ${ }^{1}$, Karen Jaceldo-Siegl ${ }^{2}$, Jing Fan ${ }^{3}$, Pramil Singh ${ }^{3}$ and Gary E. Fraser ${ }^{3} *$ \\ ${ }^{1}$ Department of Nutrition, Adventist University of São Paulo, Estrada de Itapecerica 5859, Jardim LAE, São Paulo, Brazil 05858-001 \\ ${ }^{2}$ Department of Nutrition, School of Public Health, Loma Linda University, 24951 North Circle Drive, NH 1102, Loma Linda, CA 92350 , \\ USA \\ ${ }^{3}$ Department of Epidemiology, School of Public Health, Loma Linda University, 24951 North Circle Drive, NH 2005, Loma Linda, CA 92350 , \\ USA
}

(Received 14 March 2014 - Final revision received 5 August 2014 - Accepted 11 November 2014)

Journal of Nutritional Science (2015), vol. 4, e11, page 1 of 12

doi: $10.1017 /$ jns. 2014.67

Abstract

Past dietary patterns may be more important than recent dietary patterns in the aetiology of chronic diseases because of the long latency in their development. We developed an instrument to recall vegetarian dietary patterns during the lifetime and examined its reliability of recall over 5.3 and 32.6 years on average. The short-term/5-year recall ability study (5-RAS) was done using 24690 participants from the cohort of the Adventist Health Study-2 (mean age $62 \cdot 2$ years). The long-term/33-year recall ability study (33-RAS) included an overlap population of 1721 individuals who joined the Adventist Health Study1 and Adventist Health Study-2 (mean age 72.5 years). Spearman correlation coefficients for recall of vegetarian status were 0.78 and 0.72 for the 5 -RAS and 33-RAS, respectively, when compared with 'reference' data. For both time periods sensitivity and positive predictive values were highest for the lactoovo-vegetarian and non-vegetarian patterns (vegans, lacto-ovo-vegetarians, pesco-vegetarians, semi-vegetarians and non-vegetarians). In the 5-RAS analyses, male, non-black, younger, and more educated participants, lifetime Adventists, and those with more stability of consumption of animal products generally showed higher recall ability. Somewhat similar tendencies were shown for the 33-RAS analyses. Our findings show that the instrument has higher reliability for recalled lacto-ovo-vegetarian and non-vegetarian than for vegan, semi- and pesco-vegetarian dietary patterns in both short- and long-term recalls. This is in part because these last dietary patterns were greatly contaminated by recalls that correctly would have belonged in the adjoining category that consumed more animal products.

Key words: Long-term reliability: Vegetarian diets: Dietary patterns: Adventists: Dietary recall

There is increasing evidence that non-communicable disease risks begin in fetal life and continue through to old age ${ }^{(1-3)}$. Adult non-communicable disease reflects cumulative lifetime exposures due to damaging physical and social environments. Diet plays an important role in this scenario. It is known that early consumption can influence disease risk later in life ${ }^{(4,5)}$. Moreover, dietary patterns change significantly with advancing age and estimates of recent diet by older individuals may not reflect the diet consumed over most of their adult life.
Individuals who were diagnosed with a chronic disease may be particularly prone to change their diet; thus, their present dietary pattern may reflect past diet poorly. Therefore, a lifecourse approach to dietary patterns may be more important than an exclusive focus on recent diet when exploring the relationship of diet to risk of non-communicable diseases ${ }^{(1)}$.

To date, prospective studies of the health effects of the vegetarian diet commonly practised by Adventists have focused on current consumption of animal products (mainly

Abbreviations: AHS-1, Adventist Health Study-1; AHS-2, Adventist Health Study-2; HHF, hospitalisation history form; HHF-3, third hospitalisation history form; PPV, positive predictive value; 5-RAS, short-term/5-year recall ability study; 33-RAS, long-term/33-year recall ability study; S-Stab, score of stability.

* Corresponding author: Dr Gary E. Fraser, fax +1909558 0126, email gfraser@llu.edu 
red meat, poultry, fish, dairy products and eggs) reported at baseline. These studies have shown protective effects of vegetarian diets, as they are associated with lower risk of many non-communicable diseases ${ }^{(6)}$. Furthermore, the duration of adherence to a vegetarian diet may be relevant when predicting disease and mortality ${ }^{(7-11)}$.

Therefore, the reliability of recall of vegetarian dietary patterns is of considerable interest when relating these dietary patterns to risk of diseases, such as diabetes, CVD, hypertension and cancer, among others. To investigate this, we developed an instrument to recall vegetarian dietary patterns during the lifetime and examined its reliability for recall over short- and long-term periods among older adults.

\section{Subjects and methods}

\section{Study population}

The Adventist Health Study-2 (AHS-2) is a prospective cohort study of 96335 members of the Seventh-day Adventist Church, in the USA and Canada. The design of the AHS-2 has been described in detail elsewhere ${ }^{(12)}$. Briefly, adult men and women of diverse ethnicity (mostly Caucasian or black/ African-American), and aged $\geq 30$ years were enrolled between 2002 and 2007. Participants completed a baseline questionnaire which included sections on diet, demographics, height, weight and lifestyle practices, and later, bi-annual hospitalisation history forms (HHF) administered every 2 years after the baseline questionnaire. A Californian subgroup of this population ( $n$ 1721) also participated in the Adventist Health Study-1 (AHS-1), conducted earlier (recruitment in 1976$1978)^{(6,13)}$. The present study was conducted according to the guidelines laid down in the Declaration of Helsinki and all procedures involving human subjects were approved by the Loma Linda University Institutional Review Board. Written informed consent was obtained from all subjects.

\section{Instrument to recall vegetarian dietary patterns}

The third HHF (HHF-3) was mailed from January 2009 to May 2010, and included a question that queried participants about their lifelong dietary habits: We are interested in your dietary habits at different ages. For all rows up to your present age, please fill one circle per box under each food (i.e. 5 circles each row)'. The participants were required to recall their consumption of the five foods (the columns of the response table) needed to classify their vegetarian dietary pattern. These are also foods which in previous work tended to have better short- and long-term recall ability or validity than other foods ${ }^{(14-16)}$ : meat, poultry, fish, eggs and dairy products. For each food subjects choose one of the three frequency options (never or rarely, 1-3 per month or $\geq 1$ per week) for each decade from 10 years of age to their present age, up to a maximum age of 80 years (the rows of the response table). Fig. 1(a) shows an example of response to this question.

Among the AHS-2 participants, 63919 completed the HHF-3. Since the purpose of this analysis was to evaluate the reliability of recall of vegetarian patterns, we excluded 20
$\%$ of participants who had more than one missing item on the lifelong dietary habits instrument; thus 51082 were included in the analytical population. They were younger (61.9 (SD 12.9) v. 67.3 (SD 12.9) years), less likely to be female (64.0 v. 66.1 \%), less likely to be black (16.4 v. 27.3\%) and had attained a higher educational level (44.9 v. 32.4\% college graduates) than subjects excluded. Some patterns of missing data for this question were identified, the more frequent being: one entire row $(15 \%)$, which corresponds to one decade of life or one entire column ( $2 \%)$, corresponding to one food category. The 1534 cases with only one missing response were filled by multiple imputation ${ }^{(17)}$, conditional on the variables age, race, sex and education.

Classification of vegetarian dietary patterns for each decade of life

Vegetarian dietary patterns are determined in the AHS-2 according to the frequency of intake of five animal foods (red meat, poultry, fish, eggs and dairy foods) obtained from a validated $\mathrm{FFQ}^{(18,19)}$. From these foods, three composite variables were then created by summing their reported intake frequencies: (1) meat (red meat + poultry); (2) dairy products/ eggs (dairy products + eggs); and (3) fish as a separate group. Thus, vegans are participants who reported consuming meat, fish and dairy products $<1$ time per month. Lacto-ovovegetarians are those who consume dairy products $\geq 1$ time per month, and fish and meat $<1$ time per month. Pesco-vegetarians are those who consume fish $\geq 1$ time per month and meat $<1$ time per month. Semi-vegetarians are defined as consuming meat $\geq 1$ time per month and the sum of meat and fish $<1$ time per week. Non-vegetarians are defined as those consuming meat $\geq 1$ time per week. There were no restrictions on dairy product or egg intake for pesco-, semi- and non-vegetarians. Using these definitions for the HHF questions across all decades, we were able to classify subjects according to vegetarian dietary pattern for each decade of life. Frequencies of intake were converted to daily equivalents, as follows: never or rarely $=$ zero $/ \mathrm{d}, 1-3$ per month $\approx 2$ per month $\approx 0 \cdot 066 /$ d. Since the AHS- 2 FFQ had five frequency options corresponding to $1+$ per week in the HHF-3, this open-ended frequency category was estimated separately for each food to allow estimations that more closely represented the frequency choices of the present study population. We used the 1745 overlapping subjects who answered AHS-1, AHS-2 and the lifelong instrument to estimate the average frequencies/d for the $1+$ per week category. Thus, for red meat, poultry and fish, we used 0.398/d, 0.383/d and $0 \cdot 321 / \mathrm{d}$, respectively. Fig. 1(b) shows the classification of vegetarian dietary patterns by decade of lifespan using the example of Fig. 1(a) and estimated frequencies per d.

\section{Assessment of reliability}

Reliability of the vegetarian diet pattern classification as measured by the lifelong dietary habits instrument was assessed for both recent (short-term) and remote (long-term) recall. In the short-term recall reliability study (5-RAS), the mean 


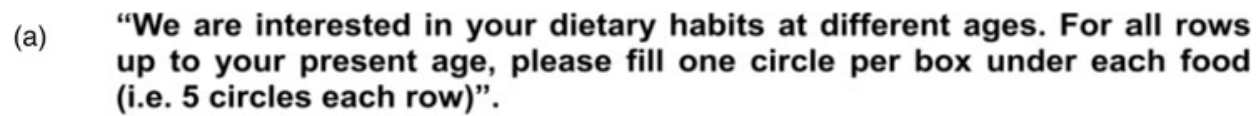

\begin{tabular}{|c|c|c|c|c|c|c|c|c|c|c|c|c|c|c|}
\hline & \multicolumn{3}{|c|}{ Red Meat } & \multicolumn{3}{|c|}{ Poultry } & \multicolumn{3}{|c|}{ Fish } & \multicolumn{3}{|c|}{ Eggs } & \multicolumn{2}{|c|}{$\begin{array}{c}\text { Dairy } \\
\text { Max chere, buthe yogr, vac) }\end{array}$} \\
\hline & $\begin{array}{l}\text { Never } \\
\text { of } \\
\text { ofely }\end{array}$ & $\begin{array}{l}1-3 \\
\text { per } \\
\text { ponth }\end{array}$ & $\begin{array}{l}1+ \\
\text { per } \\
\text { week }\end{array}$ & $\begin{array}{l}\text { Never } \\
\text { orter } \\
\text { rarely }\end{array}$ & $\begin{array}{l}1-3 \\
\text { per } \\
\text { month }\end{array}$ & $\begin{array}{l}1+ \\
\text { per } \\
\text { week }\end{array}$ & $\begin{array}{l}\text { Never } \\
\text { Iarely } \\
\text { arty }\end{array}$ & $\begin{array}{l}1-3 \\
\text { per } \\
\text { pernth }\end{array}$ & $\begin{array}{l}1+ \\
\text { per } \\
\text { week }\end{array}$ & $\begin{array}{l}\text { Never } \\
\text { orarely } \\
\text { rarly }\end{array}$ & $\begin{array}{l}1-3 \\
\text { peŕ } \\
\text { month }\end{array}$ & $\begin{array}{l}1+ \\
\text { per } \\
\text { week }\end{array}$ & $\begin{array}{l}\text { Nover } \\
\text { rarely } \\
\text { rare }\end{array}$ & $\begin{array}{ll}1-3 & 1+ \\
\text { per } & \text { per } \\
\text { month } & \text { week }\end{array}$ \\
\hline $10 \mathrm{yrs}$ old & 0 & 0 & 0 & 0 & 0 & 0 & 0 & 0 & 0 & 0 & 0 & 0 & 0 & 0 \\
\hline 20 yrs old & 잉 & 0 & 0 & $\mathrm{O}$ & 0 & $\mathrm{O}$ & 0 & 0 & 0 & 0 & $\mathrm{O}$ & 2 & 0 & 으 \\
\hline 30 yrs old & 0 & 0 & 0 & 0 & 0 & 0 & 0 & 0 & 인 & 0 & 0 & 0 & 0 & 0 \\
\hline $40 \mathrm{yrs}$ old & 0 & 0 & 0 & 0 & 0 & 0 & 0 & 0 & 0 & 0 & 0 & 0 & 0 & 임 \\
\hline 50 yrs old & 0 & 0 & 익 & 0 & O & O & 0 & 0 & 이 & 0 & 0 & 인 & 0 & 0 \\
\hline 60 yrs old & 0 & 0 & 이 & 0 & 0 & 0 & 0 & 0 & 0 & 0 & 0 & 0 & 0 & 0 \\
\hline 70 yrs old & 0 & 0 & 0 & 0 & 0 & 0 & 0 & 0 & 0 & 0 & 0 & 0 & 0 & 0 \\
\hline 80 years & 0 & 0 & 0 & 0 & 0 & 0 & 0 & 0 & 0 & 0 & 0 & 0 & 0 & 0 \\
\hline
\end{tabular}

(b)

Frequency/day:

\begin{tabular}{|c|c|c|c|c|c|c|c|c|c|}
\hline \multicolumn{2}{|r|}{ Red Meat } & \multicolumn{2}{|l|}{ Poultry } & \multicolumn{2}{|r|}{ Fish } & \multicolumn{2}{|r|}{ Eggs } & 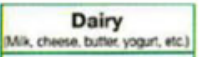 & \\
\hline \begin{tabular}{|l} 
Never \\
ovey \\
tarey
\end{tabular} & 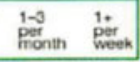 & 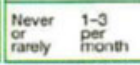 & $\begin{array}{l}1+ \\
\text { per } \\
\text { woek }\end{array}$ & \begin{tabular}{|l} 
Never \\
gavoty \\
aroty
\end{tabular} & $\begin{array}{ll}1-3 & 1+ \\
\text { pere } \\
\text { month } & 1 \\
\text { pere } \\
\text { week }\end{array}$ & $\begin{array}{l}\text { Never } \\
\text { Quvely } \\
\text { Tarely }\end{array}$ & $\left.\begin{array}{ll}1-3 & 1 \\
\text { perf } \\
\text { month } \\
\text { pert } \\
\text { week }\end{array}\right]$ & 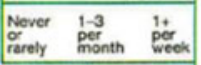 & \\
\hline 0 & 0.398 & 0.066 & 인 & 0 & 0.321 & $\mathrm{O}$ & 0.379 & 01.830 & Non-veg. \\
\hline 0 & 0 & 0.066 & 이 & 0 & 0.066 & 0 & 0.379 & 01.830 & Semi-veg. \\
\hline 0 & 0 & 0 & 이 & 0 & 이 & 0 & 0.066 이 & 01.830 & Lacto-ovo-veg. \\
\hline
\end{tabular}

Count number of equal answers from one decade to next decade

\begin{tabular}{|c|c|c|c|c|c|c|c|c|c|c|c|c|c|c|}
\hline \multicolumn{3}{|c|}{ Red Meat } & \multicolumn{3}{|c|}{ Poultry } & \multicolumn{3}{|c|}{ Fish } & \multicolumn{3}{|c|}{ Eggs } & \multicolumn{3}{|c|}{\begin{tabular}{|c|} 
Dairy \\
Ma, chene. buthe yogr, nec) \\
\end{tabular}} \\
\hline $\begin{array}{l}\text { Never } \\
\text { orver } \\
\text { tarely }\end{array}$ & $\begin{array}{l}1-3 \\
\text { perf } \\
\text { month }\end{array}$ & $\begin{array}{l}1 * \\
\text { pert } \\
\text { week }\end{array}$ & $\begin{array}{l}\text { Never } \\
\text { or } \\
\text { rarely }\end{array}$ & $\begin{array}{l}1-3 \\
\text { perf } \\
\text { month }\end{array}$ & $\begin{array}{l}1, \\
\text { per } \\
\text { week }\end{array}$ & \begin{tabular}{|l} 
Nover \\
orvely \\
rarely
\end{tabular} & $\begin{array}{l}1-3 \\
\text { per } \\
\text { month }\end{array}$ & $\begin{array}{l}1+ \\
\text { per } \\
\text { week }\end{array}$ & $\begin{array}{l}\text { Never } \\
\alpha \\
\text { rarely }\end{array}$ & $\begin{array}{l}1-3 \\
\text { per } \\
\text { month }\end{array}$ & $\begin{array}{l}1+ \\
\text { per } \\
\text { week }\end{array}$ & $\begin{array}{l}\text { Nover } \\
\alpha \\
\text { rarely } \\
\end{array}$ & $\begin{array}{l}1-3 \\
\text { pert } \\
\text { month } \\
\end{array}$ & $\begin{array}{l}1+ \\
\text { per } \\
\text { week } \\
\end{array}$ \\
\hline 0 & 0 & 0 & 0 & (8) & 0 & 0 & 0 & 0 & 0 & 0 & 0 & 0 & 0 & \\
\hline 0 & 0 & 0 & $\mathrm{O}$ & 2 & $\mathrm{O}$ & 0 & 0 & 0 & 0 & 0 & 그 & 0 & $\mathrm{O}$ & \\
\hline 5 & 0 & 0 & 0 & 0 & 0 & 0 & 0 & 0 & 0 & 0 & 0 & 0 & 0 & $\bullet$ \\
\hline
\end{tabular}

$$
\mathrm{S}-\mathrm{Stab}=\frac{\sum \text { Equal answers from one decade to next decade }}{\text { Total number of decades }-1} \times 20=\frac{5}{3-1} \times 20=50
$$

Fig. 1. (a) Lifetime dietary habits instrument with an example of responses for an individual aged between 30 and 39 years (yrs). (b) An example of the corresponding vegetarian (veg.) dietary pattern classification according to consumption of animal products by decade. Numeral values represent daily weighted frequencies. (c) An example of the corresponding calculation of the score of stability (S-Stab) in the pattern of consumption of animal products.

elapsed time was $5 \cdot 3$ years (range $1 \cdot 1-8 \cdot 9$ years) between the first measurement of diet at AHS-2 enrollment (2002-2007) and the second assessment - application of the HHF-3 (2009-2010). In the long-term recall reliability study (33-RAS), the mean elapsed time was 32.6 years (range 3134 years) between report of diet at AHS-1 (1976-1978) and application of the HHF-3. Additional criteria for selection of these samples were applied and are described below.

Both studies included only individuals who at enrollment (AHS-1 and/or AHS-2) were aged \pm 2 years from the decade year stated in the HHF-3 assessment. For example, to assess recalled diet at decade 40 by the $\mathrm{HHF}-3$, we chose subjects who were age 38-42 years during the initial assessments at baseline AHS-1 or AHS-2. For decade 50, we included subjects who were age 48-52 years, and so on. Decades 30 and 80 were exceptions. For these, we used subjects who were aged 30-32 years and 78-80 years at the initial assessment.
With these criteria for selection, the final samples of cohort members available for the studies of short- and long-term of recall reliability were 24690 and 1721 individuals, respectively. Thus, the analytic cohort used to explore long-term recall reliability of vegetarian dietary patterns was comprised of subjects who were participants in both studies (AHS-1 and AHS-2) and who also completed the HHF-3 of the AHS-2 study.

\section{Score of stability in the pattern of consumption of animal products}

Lindsted \& Kuzma ${ }^{(14)}$ created a 'diet stability score' to evaluate changes in the subjects' dietary patterns. They used this score as a determinant of the diet recall ability over 8 and 24 years ${ }^{(20)}$. We adapted this concept to the HHF-3 question about lifetime dietary habits and developed a score of stability (S-Stab) of consumption of animal products during the 
lifetime. Fig. 1(c) shows a calculation of the S-Stab applied to the example of Fig. 1(a) and (b). Possible S-Stab range from 0 to 100 . Categories of stability of consumption of animal products were defined based on the median value (82) of their distribution among the individuals who participated in the 5-RAS. Individuals with S-Stab $\leq 82$ were considered to have a less stable pattern of consumption of animal products and individuals with S-Stab $>82$ showed a more stable profile.

\section{Demographic and lifestyle exposures}

Demographic and lifestyle data were obtained from the AHS-2 baseline questionnaire. Race and ethnicity were divided into black (African, American, West Indian/Caribbean, African American, or other black) and non-black (white, non-Hispanic, Hispanic, Middle Eastern, Asian, Native Hawaiian/other Pacific Islander or American Indian). Educational level was categorised as $<$ college and $\geq$ college. Alcohol intake was defined as current consumption of any amount (yes/no), tobacco use was defined as current, past smoking (any amount), or never smoking, and current coffee consumption was scored as some or none. Typically, current smoking, or consumption of alcohol in Adventists, is uncommon. Coffee, when consumed, is usually one or two cups, or less, per d. Participants were also considered as lifetime Adventists if they were currently Adventists, also at the age of 15-25 years, and that either the mother or father who raised him/her was also Adventist when the participant was 0-15 years of age.

\section{Statistical methods}

Analyses were performed using SAS, version 9.3 (SAS Institute Inc.). Frequencies, means, percentages, standard deviations and correlations were conducted as standard descriptive statistics. To assess reliability of recalled vegetarian dietary patterns between the HHF-3 and AHS-2 (5-RAS) and the HHF-3 and AHS-1 (33-RAS) we calculated Spearman rank-order correlation coefficients, sensitivity and positive predictive values (PPV). The initial measures (reference values) of the 33- and 5-RAS were AHS-1 and AHS-2 baseline FFQ, respectively. For the calculation of Spearman coefficients, diet patterns were ranked in order of content of animal products (i.e. vegan, lacto-ovo-, pesco-, semi- and non-vegetarian). Our software allowed adjustment for only one covariate. Thus, we report the range of Spearman values adjusting for each covariate separately. Logistic regressions were used for testing the significance of sensitivity and PPV for each dietary pattern by strata of demographic factors (sex, age, race, education, duration of church membership) and by the S-Stab in the pattern of consumption of animal products. For this purpose sensitivity and PPV are defined respectively for dietary pattern $j$ as $\operatorname{pr}($ HHF $-3=\mathfrak{j} \mid$ Reference $=\mathfrak{j})$ and $\operatorname{pr}($ Reference $=\mathfrak{j} \mid$ HHF-3 $=\mathrm{j}$ ). All variables (except the stratification variables in Tables 3 and 4) were entered simultaneously into the logistic regression models. Age was dichotomised as $\leq 60$ years and $>60$ years. Overall agreement is defined as the proportion that agreed exactly on recall with the original classification.
Table 1. Selected characteristics of participants in the Adventist Health Study-2 (AHS-2) cohort who were also part of the 5-year and 33-year dietary recall studies (Percentages or mean values and standard deviations)

\begin{tabular}{|c|c|c|c|}
\hline & $\begin{array}{l}\text { Total } \\
\text { cohort }\end{array}$ & 5-year & 33-year \\
\hline Participants $(n)$ & 51082 & 24690 & 1721 \\
\hline \multicolumn{4}{|l|}{$\operatorname{Sex}(\%)$} \\
\hline Males & $36 \cdot 0$ & $36 \cdot 2$ & 37.4 \\
\hline Females & 64.0 & 63.8 & $62 \cdot 6$ \\
\hline \multicolumn{4}{|l|}{ Age at HHF-3 (\%) } \\
\hline$\leq 60$ years & $47 \cdot 1$ & $46 \cdot 5$ & 5.0 \\
\hline$>60$ years & $52 \cdot 9$ & 53.5 & 95.0 \\
\hline \multicolumn{4}{|l|}{ Age (years) } \\
\hline Mean & $61 \cdot 9$ & $62 \cdot 2$ & $72 \cdot 5$ \\
\hline SD & $12 \cdot 9$ & $12 \cdot 8$ & $8 \cdot 4$ \\
\hline \multicolumn{4}{|l|}{ Race (\%) } \\
\hline Black & $16 \cdot 4$ & $16 \cdot 0$ & 0.2 \\
\hline Non-black & $83 \cdot 6$ & 84.0 & 99.8 \\
\hline \multicolumn{4}{|l|}{ Education (\%) } \\
\hline Some college, high school or less & $55 \cdot 2$ & $55 \cdot 3$ & $47 \cdot 5$ \\
\hline College or higher & $44 \cdot 8$ & 44.7 & $52 \cdot 5$ \\
\hline \multicolumn{4}{|l|}{ Alcohol history (\%) } \\
\hline Never & 59.8 & 59.7 & $75 \cdot 2$ \\
\hline Past & $32 \cdot 7$ & $32 \cdot 8$ & 17.5 \\
\hline Current & 7.5 & 7.5 & 7.3 \\
\hline \multicolumn{4}{|l|}{ Cigarette smoking (\%) } \\
\hline Never & 82.5 & $82 \cdot 7$ & $91 \cdot 2$ \\
\hline Past & $16 \cdot 8$ & $16 \cdot 7$ & 8.6 \\
\hline Current & 0.7 & 0.6 & 0.2 \\
\hline \multicolumn{4}{|l|}{ Coffee, current (\%) } \\
\hline No & $65 \cdot 8$ & $65 \cdot 7$ & 61.5 \\
\hline Yes & $34 \cdot 2$ & $34 \cdot 3$ & 38.5 \\
\hline \multicolumn{4}{|l|}{ Lifetime SDA (\%) } \\
\hline No & $45 \cdot 1$ & 44.7 & $27 \cdot 1$ \\
\hline Yes & 54.9 & $55 \cdot 3$ & 72.9 \\
\hline \multicolumn{4}{|l|}{ Diet patterns at AHS-2 baseline (\%) } \\
\hline Vegan & 8.6 & 8.5 & 6.9 \\
\hline Lacto-ovo-vegetarian & $33 \cdot 3$ & 33.0 & 41.7 \\
\hline Pesco-vegetarian & 9.4 & 9.4 & 8.4 \\
\hline Semi-vegetarian & $5 \cdot 7$ & $5 \cdot 6$ & $7 \cdot 0$ \\
\hline Non-vegetarian & $43 \cdot 0$ & 43.5 & 36.0 \\
\hline \multicolumn{4}{|l|}{ BMI $\left(\mathrm{kg} / \mathrm{m}^{2}\right)$} \\
\hline Mean & $26 \cdot 8$ & $26 \cdot 8$ & 26.5 \\
\hline SD & $5 \cdot 8$ & $5 \cdot 8$ & $5 \cdot 0$ \\
\hline \multicolumn{4}{|l|}{$\begin{array}{l}\text { Score of stability of consumption of } \\
\text { animal products }(\%)\end{array}$} \\
\hline$\leq 82$ (the median) & $50 \cdot 3$ & $50 \cdot 0$ & 34.2 \\
\hline$>82$ & 49.7 & $50 \cdot 0$ & 65.8 \\
\hline
\end{tabular}

HHF-3, hospitalisation history form 3; SDA, Seventh-day Adventist.

\section{Results}

The 24690 subjects in the 5-RAS represented the total AHS-2 cohort very well, both with respect to demographic variables and vegetarian dietary patterns (Table 1). As expected, however, the 1721 participants of the 33-RAS were older. Their mean age ( 72.5 years) was 10 years higher than that of the 5 -RAS (62.2 years). Since this is a subgroup of participants of the AHS-1, a study designed mainly to study only white non-Hispanic California Adventists, there were very few black subjects (Table 1). As compared with 5-RAS participants, 33-RAS participants were white, better educated, reported a higher proportion with never use of alcohol and tobacco, were more likely to be current coffee consumers and to be lifelong Seventh-day Adventists, and had generally 
Table 2. Overall reliability of the vegetarian dietary patterns over 5-year and 33-year dietary recall periods, as measured by sensitivity, positive predictive value (PPV) and Spearmans $\rho$ correlation coefficients

\begin{tabular}{|c|c|c|c|c|c|c|c|c|}
\hline \multirow[b]{2}{*}{ Vegetarian dietary pattern } & \multicolumn{3}{|c|}{ 5-year } & \multicolumn{3}{|c|}{ 33-year } & \multicolumn{2}{|c|}{ Spearman's $\rho^{*}$} \\
\hline & AHS-2 $(n) \dagger$ & Sensitivity (\%) & PPV (\%) & AHS-1 $(n) \dagger$ & Sensitivity (\%) & PPV (\%) & 5-year & 33-year \\
\hline Vegan & 2103 & 75 & 42 & 18 & 50 & 16 & 0.78 & 0.72 \\
\hline Lacto-ovo-vegetarian & 8150 & 71 & 77 & 818 & 81 & 81 & & \\
\hline Pesco-vegetarian & 2316 & 42 & 49 & 25 & 28 & 16 & & \\
\hline Semi-vegetarian & 1393 & 41 & 19 & 310 & 25 & 37 & & \\
\hline Non-vegetarian & 10728 & 70 & 90 & 550 & 77 & 71 & & \\
\hline Total & 24690 & & & 1721 & & & & \\
\hline
\end{tabular}

AHS-2, Adventist Health Study-2; AHS-1, Adventist Health Study-1.

* Spearman's correlation where the dietary patterns were ranked in the order vegan, lacto-ovo-vegetarian, pesco-vegetarian, semi-vegetarian and non-vegetarian.

$\dagger$ Number of individuals with survey response.

higher scores of stability of consumption of animal products during the lifespan. This group also showed higher proportions of lacto-ovo-vegetarians and semi-vegetarians, and lower proportion of vegans, pesco-vegetarians and nonvegetarians.

Table 2 presents overall (without covariate adjustment) recall reliability as estimated by Spearman's correlations and reliability of assignment of individual patterns as estimated by sensitivity and PPV in the 5-RAS and 33-RAS. As expected, the 33-RAS showed lower overall reliability than the 5-RAS, but Spearman's correlation coefficients from both studies were above $0.70(0.78$ and 0.72 for the 5-RAS and 33-RAS, respectively). In both studies sensitivity and PPV were higher for lacto-ovo-vegetarian and non-vegetarian dietary patterns, while semi-vegetarian and pesco-vegetarian patterns had poorer reliability. The vegan dietary pattern had comparatively better sensitivity in the 5-RAS, but lower sensitivity and PPV in the 33-RAS. Except for recalled lacto-ovo-vegetarian and non-vegetarian dietary patterns, sensitivity and PPV tended to decrease from 5 to 33 years of recall.

Table 3 shows that the overall 5-year reliabilities of recalled dietary patterns were moderately, but often significantly, lower among blacks, older and less educated individuals, and higher among lifetime Adventists, but with some variations between dietary patterns. An exception is the higher sensitivity among black pesco-vegetarians compared with white pescovegetarians. Sensitivity was usually higher among vegans, lacto-ovo-vegetarians and non-vegetarians compared with other vegetarian patterns.

Somewhat similar tendencies were observed for the 33-RAS (Table 4), but with few statistically significant results when comparing between subjects in the different categories of that stratification variable. Overall agreement tended to be lower among less educated, non-lifetime Adventists and those with lower stability scores. The low number of black and younger participants limited the precision of comparisons by age and race categories, which are not shown.

It was also noticeable that PPV, and in some cases also sensitivity, tended to be higher among those who had higher S-Stab. This was especially true for lacto-ovo-vegetarians and for non-vegetarians. It seems that individuals with fewer changes in their pattern of consumption of animal products during their lifetime showed better recall ability of their past diet, over this longer period. Overall agreement generally showed similar trends to those reported above, and results were typically in the 64-70\% range with no clear differences between the 5- and 33-year follow-ups. Again the most striking loss of agreement was among those with lower dietary stability.

When subjects' recollections of their previous diet (using the HHF-3) were different from baseline data of either the 5-RAS or 33-RAS (data not shown), these misperceptions tended to reallocate subjects who were originally nearer to the closest adjoining category that consumed fewer animal products, into that adjoining category (Table 5).

Referring to Table 5, a total of 3807 participants recalled themselves as being vegans at their baseline age. Of these, $1583(42 \%)$ were true positives and $58 \%$ were false positives. The majority of the false positives $(71 \%)$ were in fact originally classified as lacto-ovo-vegetarians. Interestingly, when we examined their baseline daily frequencies of dairy products and eggs we found that these misclassified individuals originally consumed lower amounts of dairy products and eggs $(0 \cdot 58 / d)$ than all lacto-ovo-vegetarians $(1 \cdot 29 / d)$.

Similarly, a total of 1980 individuals were classified as pesco-vegetarians in the HHF-3. Of these, $49 \%$ were true positives and $51 \%$ were false positives. Most of the false positives $(61 \%)$ were in fact originally non-vegetarians who at baseline reported higher average daily frequency of fish $(0 \cdot 31 / d)$ and lower daily frequency of meat $(0 \cdot 32 / d)$ than all non-vegetarians $(0 \cdot 23 / \mathrm{d}$ and $0.59 / \mathrm{d}$, respectively).

The same pattern was also observed among the 2958 participants who were classified as semi-vegetarians in the HHF-3. Of these, only $19 \%$ were true positives and $81 \%$ were false positives. However, most of the false positives $(76 \%)$ were in fact originally non-vegetarians who had lower daily frequency of meat and fish than all non-vegetarians $(0.38 / \mathrm{d} v .0 .59 / \mathrm{d}$ and $0 \cdot 17 / \mathrm{d} v \cdot 0 \cdot 23 / \mathrm{d}$, respectively).

A different pattern was found for those who recalled themselves as being lacto-ovo-vegetarians ( $n$ 7523). Among them $77 \%$ were true positives and $23 \%$ were false positives. Most of the false-positive cases were either pesco-vegetarians $(7 \%)$ who ate less fish $(0 \cdot 13 / \mathrm{d})$ than all pesco-vegetarians $(0 \cdot 21 / \mathrm{d})$ or non-vegetarians $(7 \%)$ who ate less meat $(0 \cdot 33 /$ d) than all non-vegetarians $(0 \cdot 59 / \mathrm{d})$. A total of $90 \%$ of those who recalled themselves as being non-vegetarians ( $n$ 8426) were true positives. 
Table 3. Reliability of adult recall of classification of vegetarian dietary patterns in the 5-year recall ability study by demographic and lifestyle factors and stability of consumption of animal products $t$

\begin{tabular}{|c|c|c|c|c|c|c|}
\hline \multirow[b]{2}{*}{ By sex } & \multicolumn{2}{|c|}{ Sensitivity (\%) } & \multicolumn{2}{|c|}{ Positive predictive value (\%) } & \multicolumn{2}{|c|}{ Overall agreement (\%) } \\
\hline & Males ( $n$ 8945) & Females ( $n 15745)$ & Males & Females & Males & Females \\
\hline Vegan & 68 & 66 & 51 & 49 & 68 & 66 \\
\hline Lacto-ovo-vegetarian & 68 & 70 & 74 & 72 & & \\
\hline Pesco-vegetarian & 42 & 39 & 53 & 50 & & \\
\hline Semi-vegetarian & 42 & 39 & 19 & 18 & & \\
\hline Non-vegetarian & $71^{*}$ & 68 & 88 & 89 & & \\
\hline Spearman's $\rho \ddagger$ & $0.76-0.79$ & $0.75-0.78$ & & & & \\
\hline By race & Non-blacks (n 20732 ) & Blacks ( $n$ 3958) & Non-blacks & Blacks & Non-blacks & Blacks \\
\hline Vegan & 68 & 62 & $51^{*}$ & 41 & 67 & 64 \\
\hline Lacto-ovo-vegetarian & $71^{*}$ & 60 & $74^{*}$ & 66 & & \\
\hline Pesco-vegetarian & $39^{*}$ & 49 & 51 & 52 & & \\
\hline Semi-vegetarian & $42^{*}$ & 32 & $21^{*}$ & 10 & & \\
\hline Non-vegetarian & $69^{*}$ & 73 & $88^{*}$ & 90 & & \\
\hline Spearman's $\rho \ddagger$ & $0.75-0.79$ & $0.70-0.73$ & & & & \\
\hline By age§ & Older (n 13210$)$ & Younger (n 11 480) & Older & Younger & Older & Younger \\
\hline Vegan & $71^{*}$ & 62 & $45^{\star}$ & 55 & 64 & 70 \\
\hline Lacto-ovo-vegetarian & $63^{*}$ & 75 & $68^{*}$ & 78 & & \\
\hline Pesco-vegetarian & 39 & 41 & 50 & 52 & & \\
\hline Semi-vegetarian & 38 & 43 & 17 & 20 & & \\
\hline Non-vegetarian & $63^{*}$ & 76 & $88^{*}$ & 89 & & \\
\hline Spearman's $\rho \ddagger$ & $0.74-0.78$ & $0.78-0.80$ & & & & \\
\hline By education§ & Less educated ( $n 13645)$ & More educated ( $n 11045)$ & Less educated & More educated & Less educated & More educated \\
\hline Vegan & 65 & 69 & 49 & 49 & 65 & 68 \\
\hline Lacto-ovo-vegetarian & $67^{\star}$ & 72 & $70^{*}$ & 77 & & \\
\hline Pesco-vegetarian & $38^{*}$ & 43 & 49 & 53 & & \\
\hline Semi-vegetarian & 40 & 40 & 18 & 20 & & \\
\hline Non-vegetarian & 70 & 69 & 88 & 89 & & \\
\hline Spearman's $\rho \ddagger$ & $0.74-0.77$ & $0.77-0.80$ & & & & \\
\hline By lifetime SDA§ & Non-lifetime SDA ( $n 11$ 049) & Lifetime SDA ( $n 13$ 641) & Non-lifetime SDA & Lifetime SDA & Non-lifetime SDA & Lifetime SDA \\
\hline Vegan & $71^{*}$ & 63 & $49^{*}$ & 44 & 65 & 68 \\
\hline Lacto-ovo-vegetarian & $67^{*}$ & 71 & $71^{*}$ & 75 & & \\
\hline Pesco-vegetarian & 39 & 41 & 49 & 52 & & \\
\hline Semi-vegetarian & 37 & 42 & $16^{*}$ & 21 & & \\
\hline
\end{tabular}




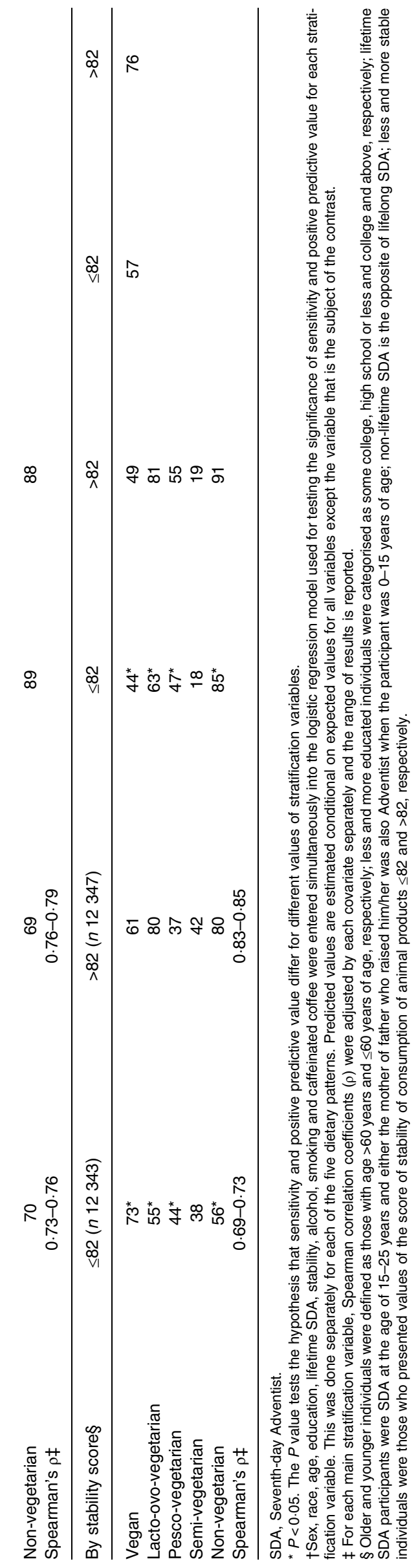

As the original non-vegetarian and lacto-ovo-vegetarian categories are large, proportionately small erroneous transfers out of these categories on recall overwhelm the number of subjects who recall accurately in the smaller adjoining dietary categories. Thus, most of the error measured by PPV (false positives) was derived from this type of misclassification.

\section{Discussion}

In this report we describe an instrument designed to recall vegetarian dietary patterns during the lifetime and evaluated the reliability of recall of dietary patterns over $5 \cdot 3$ and 32.6 years on average. We found that the instrument has higher reliability for recalled lacto-ovo-vegetarian and non-vegetarian dietary patterns compared with vegan, semi- and pesco-vegetarian dietary patterns in both short- and long-term recalls. In the 5-RAS, males, non-blacks, younger and more educated participants, lifetime Adventists, and those with higher stability of consumption of animal products had greater reliability. Somewhat similar tendencies were shown for the 33-RAS. The subjects misclassified by recall to the three less reliable categories (vegans, pesco- and semi-vegetarians) often tended to recall to the nearest 'more ideal' category, from a vegetarian perspective. Such misclassification might be explained arithmetically due to the limited consumption frequency categories available in the $\mathrm{HHF}-3$ or may indicate social desirability bias.

The assessment of past diet, and its reliability and relative validity have been previously investigated ${ }^{(3,16,21-30)}$ with diet recalls from 1 year to 48 years later. As compared with current diet, others have found that the recalled diet usually provides a more reliable estimate of past diet, both for nutrients and food group variables. Five studies have previously investigated recall ability in Adventist populations ${ }^{(14-16,20,31)}$. The factors found to influence recall reliability include the duration of recall period, data collection methods, the respondents' demographic characteristics (sex, age, etc.) and the dietary factors involved $^{(22,25)}$.

\section{Previous assessments of lifetime diet stability in Adventists}

The present results extend the work of Lindsted \& Kuzma ${ }^{(14,15)}$, who also studied an Adventist population and observed a statistically significant trend of decreasing recall reliability with increasing age. They investigated the determinants of reliability of short- $(8 \text { years })^{(31)}$ and long-term diet recalls $(24 \text { years })^{(20)}$ among participants of the Adventist Mortality Study. Unlike other studies, our instrument did not collect information about many food items relating to one single age in the past. Instead, we collected information of only five food items but covered all previous decades of life. This could have involved an additional challenge to our respondents, especially older ones, who had to recall a larger number of previous decades.

Studies have shown that recall ability is dependent on a number of factors related to diet, including the frequency of consumption of food items and the importance placed on them. Recall seems to be most reliable for foods eaten 
Table 4. Reliability of adult recall of classification of vegetarian dietary patterns in the 33-year recall ability study by demographic and lifestyle factors and stability of consumption of animal products $\dagger$

\begin{tabular}{|c|c|c|c|c|c|c|}
\hline \multirow[b]{2}{*}{ By gender } & \multicolumn{2}{|c|}{ Sensitivity (\%) } & \multicolumn{2}{|c|}{ Positive predictive value (\%) } & \multicolumn{2}{|c|}{ Overall agreement } \\
\hline & Males $(n 643)$ & Females $(n$ 1078) & Males & Females & Males & Females \\
\hline Vegan & - & - & 19 & 29 & 69 & 68 \\
\hline Lacto-ovo-vegetarian & 78 & 79 & 79 & 79 & & \\
\hline Pesco-vegetarian & - & - & - & - & & \\
\hline Semi-vegetarian & 28 & 21 & 47 & 35 & & \\
\hline Non-vegetarian & 75 & 76 & 71 & 71 & & \\
\hline Spearman's $\rho \ddagger$ & $0.69-0.73$ & $0.69-0.72$ & & & & \\
\hline By education§ & Less educated ( $n 818)$ & More educated ( $n$ 903) & Less educated & More educated & Less educated & More educated \\
\hline Vegan & - & - & 35 & 17 & 67 & 70 \\
\hline Lacto-ovo-vegetarian & 76 & 81 & 78 & 79 & & \\
\hline Pesco-vegetarian & - & - & - & - & & \\
\hline Semi-vegetarian & 24 & 23 & 37 & 42 & & \\
\hline Non-vegetarian & 77 & 74 & 71 & 72 & & \\
\hline Spearman's $\rho \ddagger$ & $0.67-0.70$ & $0.67-0.72$ & & & & \\
\hline By lifetime SDA§ & Non-lifetime SDA ( $n$ 466) & Lifetime SDA ( $n$ 1255) & Non-lifetime SDA & Lifetime SDA & Non-lifetime SDA & Lifetime SDA \\
\hline Vegan & - & - & 23 & 26 & 65 & 70 \\
\hline Lacto-ovo-vegetarian & 78 & 79 & 75 & 80 & & \\
\hline Pesco-vegetarian & - & - & - & - & & \\
\hline Semi-vegetarian & 22 & 25 & 36 & 41 & & \\
\hline Non-vegetarian & 72 & 77 & 74 & 70 & & \\
\hline Spearman's $\rho \ddagger$ & $0.65-0.69$ & $0.70-0.73$ & & & & \\
\hline By stability score§ & $\leq 82(n 588)$ & $>82(n 1133)$ & $\leq 82$ & $>82$ & $\leq 82$ & $>82$ \\
\hline Vegan & - & - & 22 & 26 & 61 & 72 \\
\hline Lacto-ovo-vegetarian & $67^{*}$ & 83 & $72^{*}$ & 81 & & \\
\hline Pesco-vegetarian & - & - & - & - & & \\
\hline Semi-vegetarian & 28 & 22 & 45 & 37 & & \\
\hline Non-vegetarian & 72 & 77 & $63^{*}$ & 75 & & \\
\hline Spearman's $\rho \ddagger$ & $0.55-0.58$ & $0.75-0.79$ & & & & \\
\hline
\end{tabular}

- , Too few subjects in this category (estimates unstable); SDA, Seventh-day Adventist.

* $P<0.05$. The $P$ value tests the hypothesis that sensitivity and positive predictive value differ for different values of stratification variables.

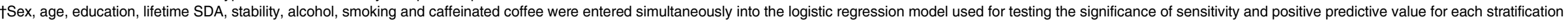

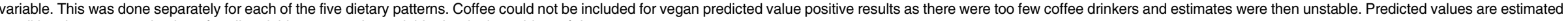
conditional on expected values for all variables except the variable that is the subject of the contrast.

‡ For each main stratification variable, Spearman correlation coefficients $(\rho)$ were adjusted by each covariate separately and the range of results is reported.

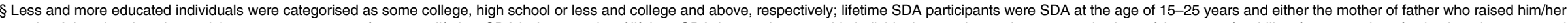

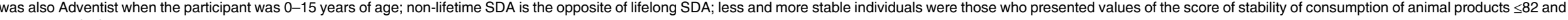
$>82$, respectively. 
rarely ${ }^{(22,23)}$. Lindsted \& Kuzma ${ }^{(15)}$ observed that the 8 -year recall reliability was higher for food items considered as 'important' by Adventist traditions and recommendations, such as meat, beef, non-fat milk, low-fat milk, buttermilk and eggs. Similar results were found by the same authors for 24 -year recall ${ }^{(14)}$. For example, foods that are often avoided, such as meat use in vegetarians, were recalled well. Fraser et $a l^{(16)}$ found similar results when addressing the validity of 20-year dietary recall among Californian Adventists. Beef and chicken, and all meats combined, were recalled with validity coefficients of greater than $0 \cdot 4$. The highest coefficient was for hamburgers $(0 \cdot 55-0.88)$ based on the different methods of scoring the FFQ. Eggs, whole milk and fish had correlation coefficients of greater than $0 \cdot 3$. Again, these were foods observed to be 'important' to many Adventists.

In the present study, we asked only about foods used to classify vegetarian dietary patterns (red meat, poultry, fish, eggs and dairy products). Many Adventists have a special interest in diet and will long ago have made decisions regarding these foods. This fact may have helped the participants of the present study to remember their previous consumption of these food items. For this population, consumption of animal products probably became components of the so-called 'permanent diet memory' that reflects the basal consumption rate of 'usual diet' and includes category labels, such as: 'foods I eat' or 'foods I never eat'. Memories of 'usual' dietary habits are stored as permanent and their report has been described as independent of time ${ }^{(32)}$. This permanent diet memory can be both a strength and a weakness in the analysis of dietary intake. It is a weakness in that it drives social desirability bias, which probably accounts for the results of Table 5 where many subjects tend to recall fewer animal products than they actually consumed. If animal products have an adverse effect on health, this may somewhat exaggerate the apparent effects of these foods. On the other hand, for individuals who choose a diet for health or philosophical reasons, the permanent diet memory is an advantage as it helps them recall which foods they avoided, and should also improve recall ability. It is unclear whether these findings will apply to the general population.

Other demographic characteristics that may influence recall reliability were examined by Kuzma \& Lindsted ${ }^{(20,31)}$. They found in their 8-year recall study that the best predictors of recall were diet stability, vegetarian status, higher education, higher income, and, as already mentioned, younger age ${ }^{(31)}$. In their 24-year recall study, the best predictors were also diet stability, vegetarian status, higher education and, to a lesser extent, regular church attendance ${ }^{(20)}$. Overall, the key determinant of diet recall was diet stability over time. Accordingly, highest correlation coefficients were observed for subjects who reported no dietary change ${ }^{(22,23)}$. We also found that lifetime Adventists with higher education who had had more stable dietary habits tend to perform better when recalling foods that determined their vegetarian dietary patterns.

Although many studies have explored agreement between recalled and original diet for nutrients and food groups, as far as we are aware, no other study has focused on the 
reliability of recall of vegetarian dietary patterns. The closest approach was the study of Eysteinsdottir et al. ${ }^{(30)}$ in which midlife diet was recalled 18 to 19 years later when subjects were categorised into five groups according to level of consumption of each food. Interestingly, cross-classification showed that 16-59\% were classified into the same group and 43-91\% into the same or adjacent group and 0-14\% were grossly misclassified. The same trend was observed in the present study when in both the 5-RAS and 33-RAS, the lifetime dietary habits instrument in the HHF-3, when incorrect, tended to classify subjects into the closest adjoining category that consumed fewer animal products. Probably this is an example of social desirability bias in this population. In the present paper we chose to focus on the recall of vegetarian dietary patterns because these patterns, although defined by few foods, have large differences in consumption of many nutrients, vitamins and minerals ${ }^{(33)}$. Moreover, they are associated with differences in many disease outcomes and total mortality $^{(6,34)}$. For this reason, some believe that dietary pattern analysis is more useful in predicting disease risk than individual foods or nutrients ${ }^{(35-37)}$.

\section{Duration of recall period and reliability}

Others have reported that correlations between the original and recalled reports decrease as the recall time becomes longer ${ }^{(22,23,29)}$. This was also observed in the present results as the Spearman correlation coefficients, sensitivity and PPV tended to decrease from the 5-RAS to the 33-RAS.

Previous studies showed that, overall, sex does not appear to influence recall ability ${ }^{(22,23)}$. This was confirmed by the present work, although men had slightly higher correlations in both the 5-RAS and 33-RAS.

\section{Age and reliability of recall}

Advanced age might be related to decreased recall ability to access past diet ${ }^{(22)}$. However, some studies did not show differences in recall reliability with increased age ${ }^{(22,23)}$. It seems that long-term memory often remains intact despite reductions in short-term memory. Therefore accuracy of the memory of foods consumed does not necessarily decline over time ${ }^{(25,38)}$. However, reliability of dietary assessment methods applied in older individuals is dependent on the group of elderly individuals under study and the type of information required ${ }^{(39)}$. To date, we know of only two other studies that have evaluated diet recall over more than 30 years ${ }^{(25,29,40)}$. They assessed recall of adolescent diet with better correlations after 32 years ${ }^{(40)}$ than after 48 years $^{(29)}$. Although Dwyer et al. ${ }^{(40)}$ concluded that the recall of food intake in the distant past may be a sufficiently valid estimate of past intake, the conclusion by Chavarro et al. ${ }^{(29)}$ was that their instrument did not measure overall adolescent diet with adequate validity when completed by middle-aged and older adults. In the present study, recall of vegetarian dietary patterns from the distant past (33 years) had good long-term recall reliability for lacto-ovo-vegetarian and non-vegetarian patterns, while pesco-vegetarian and semi-vegetarian patterns had lower recall reliability. However, the lowest Spearman's correlation coefficient for the 33-RAS (thus across all dietary patterns) was 0.55 in the group with the lower stability score.

\section{Limitations}

One of the limitations of the present study is that the exclusion criteria (participants who had more than one missing response on the lifelong dietary habits instrument) eliminated $20 \%$ of the participants from the study. The individuals excluded were demographically different from the remaining participants. They were older, more likely to be black and women, and had a lower educational level on average. Thus it is also possible that this group may have poorer recall ability. A proportion of the remaining individuals left one missing response on the instrument $(3 \% ; n$ 1534). We filled these blank answers by multiple imputation, a strategy that requires the assumption that these missing data are missing at random. This assumption is difficult to verify, but with such a small percentage of missing data, even moderate deviations from this assumption will not have much influence ${ }^{(41)}$.

The method of data collection is one of the factors influencing recall reliability. Previous studies showed lower correlations for studies that used different instruments for original and recalled diet assessments ${ }^{(22)}$. Therefore, an important limitation of the present study is that the instrument used as the referent measure is different from the short set of questions about lifelong dietary habits used in the HHF-3. For example, the latter focused on the composite intakes of five foods from animal sources whereas the referent measure was a more comprehensive FFQ which included multiple questions about each of the five foods. Intake of animal foods from the HHF-3 instrument may be underestimated relative to the more comprehensive food list from the referent FFQ. The effect could be misclassification of dietary patterns toward a more plant-based diet (which is what we observed), so attenuating the reliability measurements.

\section{Conclusion}

To date, most studies of Adventist populations have used the classification of the vegetarian dietary patterns based on the recent consumption of animal products. However, some studies showed that the duration of adherence to a vegetarian diet is important when addressing mortality and risk of disease $\mathrm{e}^{(7-11)}$. We conclude that our instrument to recall vegetarian dietary patterns is an inexpensive, useful tool with which to reliably classify lacto-ovo- and non-vegetarian dietary patterns across long periods of life in this population. The instrument does classify some subjects who originally claimed to belong in these patterns, but who consumed relatively fewer animal products, into the next 'more vegetarian' pattern. This has an adverse impact on the reliability of the less frequent dietary patterns.

\section{Acknowledgements}

We acknowledge the support of Mrs Hannelore Bennett, Research Associate, Adventist Health Studies, School of Public Health, Loma Linda University. 
The sources of funding for the present study were National Institutes of Health/National Cancer Institute (NIH/NCI) grant no. 5U01CA152939, World Cancer Research Fund, UK grant no. 2009/93 and US Department of Agriculture (USDA) grant no. 2010-38938-20924. The NIH/NCI, World Cancer Research Fund and the USDA had no role in the design, analysis or writing of this article.

The contributions of each author were: M. C. T. M. wrote the initial draft of the paper and directed the analysis; K. J.-S. was an active collaborator with M. C. T. M. at each step and reviewed the manuscript many times; J. F. was the statistician/programmer who conducted the statistical analyses working closely with K. J.-S. and M. C. T. M.; P. S. suggested important additional analyses and reviewed the manuscript; G. E. F. provided funding for the data collection, conceived of the idea and design of this project, and worked closely with M. C. T. M., reviewing the manuscript and the analysis several times.

There are no conflicts of interest to report.

\section{References}

1. Darnton-Hill I, Nishida C \& James WP (2004) A life course approach to diet, nutrition and the prevention of chronic diseases. Public Health Nutr 7, 101-121.

2. Mann J (2000) Stemming the tide of diabetes mellitus. Lancet 356, 1454-1455.

3. Ambrosini GL, van Roosbroeck SA, Mackerras D, et al. (2003) The reliability of ten-year dietary recall: implications for cancer research. J Nutr 133, 2663-2668.

4. Nicklas TA (2003) Calcium intake trends and health consequences from childhood through adulthood. J Am Coll Nutr 22, 340-356.

5. St-Onge MP, Keller KL \& Heymsfield SB (2003) Changes in childhood food consumption patterns: a cause for concern in light of increasing body weights. Am J Clin Nutr 78, 1068-1073.

6. Fraser GE (2003) Diet, Life Expectancy, and Chronic Disease: Studies of Seventh-Day Adventists and Other Vegetarians. Oxford and New York: Oxford University Press.

7. Singh PN, Sabate J \& Fraser GE (2003) Does low meat consumption increase life expectancy in humans? Am J Clin Nutr 78, Suppl. 3, 526S-532S.

8. Key TJ, Fraser GE, Thorogood M, et al. (1999) Mortality in vegetarians and nonvegetarians: detailed findings from a collaborative analysis of 5 prospective studies. Am J Clin Nutr 70, Suppl. 3, 516S-524S.

9. Chang-Claude J \& Frentzel-Beyme R (1993) Dietary and lifestyle determinants of mortality among German vegetarians. Int J Epidemiol 22, 228-236.

10. Fraser GE (1999) Associations between diet and cancer, ischemic heart disease, and all-cause mortality in non-Hispanic white California Seventh-day Adventists. Am J Clin Nutr 70, Suppl. 3, 532S-538S.

11. Chang-Claude J, Frentzel-Beyme R \& Eilber U (1992) Mortality pattern of German vegetarians after 11 years of follow-up. Epidemiology 3, 395-401.

12. Butler TL, Fraser GE, Beeson WL, et al. (2008) Cohort profile: The Adventist Health Study-2 (AHS-2). Int J Epidemiol 37, 260-265.

13. Beeson WL, Mills PK, Phillips RL, et al. (1989) Chronic disease among Seventh-day Adventists, a low-risk group. Rationale, methodology, and description of the population. Cancer 64, 570-581.

14. Lindsted KD \& Kuzma JW (1989) Long-term (24-year) recall reliability in cancer cases and controls using a 21-item food frequency questionnaire. Nutr Cancer 12, 135-149.
15. Lindsted KD \& Kuzma JW (1990) Reliability of eight-year diet recall in cancer cases and controls. Epidemiology 1, 392-401.

16. Fraser GE, Lindsted KD, Knutsen SF, et al. (1998) Validity of dietary recall over 20 years among California Seventh-day Adventists. Am J Epidemiol 148, 810-818.

17. Schafer JL (1997) Inference by data augmentation. In Analysis of Incomplete Multivariate Data. Monographs on Statistics and Applied Probability 72, pp. 89-146 [J Schafer, editor]. Boca Raton, FL: Chapman and Hall/CRC.

18. Jaceldo-Siegl K, Knutsen SF, Sabate J, et al. (2010) Validation of nutrient intake using an FFQ and repeated $24 \mathrm{~h}$ recalls in black and white subjects of the Adventist Health Study-2 (AHS-2). Public Health Nutr 13, 812-819.

19. Jaceldo-Siegl K, Fan J, Sabate J, et al. (2011) Race-specific validation of food intake obtained from a comprehensive FFQ: the Adventist Health Study-2. Public Health Nutr 14, 1988-1997.

20. Kuzma JW \& Lindsted KD (1989) Determinants of long-term (24-year) diet recall ability using a 21 -item food frequency questionnaire. Nutr Cancer 12, 151-160.

21. Persson PG, Ahlbom A \& Norell SE (1990) Retrospective versus original information on diet: implications for epidemiological studies. Int J Epidemiol 19, 343-348.

22. Friedenreich CM, Slimani N \& Riboli E (1992) Measurement of past diet: review of previous and proposed methods. Epidemiol Rev 14, 177-196.

23. Wilkens LR, Hankin JH, Yoshizawa CN, et al. (1992) Comparison of long-term dietary recall between cancer cases and noncases. $\mathrm{Am} \mathrm{J}$ Epidemiol 136, 825-835.

24. Takatsuka N, Kawakami N, Kawai K, et al. (1996) Validation of recalled food intake in the past in a Japanese population. J Epidemiol 6, 9-13.

25. Dwyer JT \& Coleman KA (1997) Insights into dietary recall from a longitudinal study: accuracy over four decades. Am J Clin Nutr 65, Suppl. 4, 1153S-1158S.

26. Wolk A, Bergstrom R, Hansson LE, et al. (1997) Reliability of retrospective information on diet 20 years ago and consistency of independent measurements of remote adolescent diet. Nutr Cancer 29, 234-241.

27. Malila N, Virtanen M, Pietinen P, et al. (1998) A comparison of prospective and retrospective assessments of diet in a study of colorectal cancer. Nutr Cancer 32, 146-153.

28. Maruti SS, Feskanich D, Rockett HR, et al. (2006) Validation of adolescent diet recalled by adults. Epidemiology 17, 226-229.

29. Chavarro JE, Rosner BA, Sampson L, et al. (2009) Validity of adolescent diet recall 48 years later. Am J Epidemiol 170, 1563-1570.

30. Eysteinsdottir T, Gunnarsdottir I, Thorsdottir I, et al. (2011) Validity of retrospective diet history: assessing recall of midlife diet using food frequency questionnaire in later life. J Nutr Health Aging 15, 809-814.

31. Kuzma JW \& Lindsted KD (1990) Determinants of eight-year diet recall ability. Epidemiology 1, 386-391.

32. Wirfält E (1998) Cognitive aspects of dietary assessment. Scand J Nutr 42, 56-59.

33. Rizzo NS, Jaceldo-Siegl K \& Fraser GE (2012) Differences and similarities in dietary pattern and nutrient profiles between the sexes and blacks and whites. The Adventist Health Study 2. Circulation 125, AP077.

34. Fraser GE (2009) Vegetarian diets: what do we know of their effects on common chronic diseases? Am J Clin Nutr 89, 1607S$1612 S$.

35. Jacques PF \& Tucker KL (2001) Are dietary patterns useful for understanding the role of diet in chronic disease? Am J Clin Nutr 73, 1-2.

36. Schulze MB \& Hu FB (2002) Dietary patterns and risk of hypertension, type 2 diabetes mellitus, and coronary heart disease. Curr Atheroscler Rep 4, 462-467.

37. Hu FB (2002) Dietary pattern analysis: a new direction in nutritional epidemiology. Curr Opin Lipidol 13, 3-9. 
38. Krall EA, Dwyer JT \& Coleman KA (1988) Factors influencing accuracy of dietary recall. Nutr Res 8, 829-841.

39. Vanstaveren WA, Degroot LCPGM, Blauw YH, et al. (1994) Assessing diets of elderly people: problems and approaches. Am J Clin Nutr 59, S221-S223.
40. Dwyer JT, Gardner J, Halvorsen K, et al. (1989) Memory of food intake in the distant past. Am J Epidemiol 130, 1033-1046.

41. Fraser G \& Yan R (2007) Guided multiple imputation of missing data: using a subsample to strengthen the missing-at-random assumption. Epidemiology 18, 246-252. 